\title{
Research and outreach can lessen the overall burden of diabetes in farmworkers
}

by Lucia L. Kaiser, Anna C. Martin

and Francene M. Steinberg

Type 2 diabetes is increasing rapidly in the United States and Latin America and contributes significantly to the rise in health care spending. Diabetes increases the risk of cardiovascular disease, renal failure and blindness, and leads to other complications. Type 2 diabetes and its complications can be delayed in high-risk individuals through a healthy lifestyle and ongoing medical care. Some research suggests a relationship between diabetes and other underlying metabolic conditions, either as predisposing factors or as adverse outcomes of occupational exposures in farmworkers. UC Cooperative Extension can have a greater impact on the health and safety of California's workforce by filling in research gaps and strengthening collaborations.

IN the United States, diabetes affects an estimated 23.6 million people, most of whom do not achieve optimal control of their blood glucose levels (Valitutto 2008). Fueled by the obesity epidemic, this disease is expected to affect 48.3 million people by 2050 (Narayan et al. 2006). Globally, the number of people with diabetes is projected to double over the next 30 years, with much of the increase expected to occur in developing countries (Chaturvedi 2007). We review trends in type 2 diabetes and provide a perspective on the implications for occupational health and safety programs targeting farmworker populations. We also discuss ways that outreach and research programs of the University of California and UC Cooperative Extension can help to reduce the burden of diabetes.

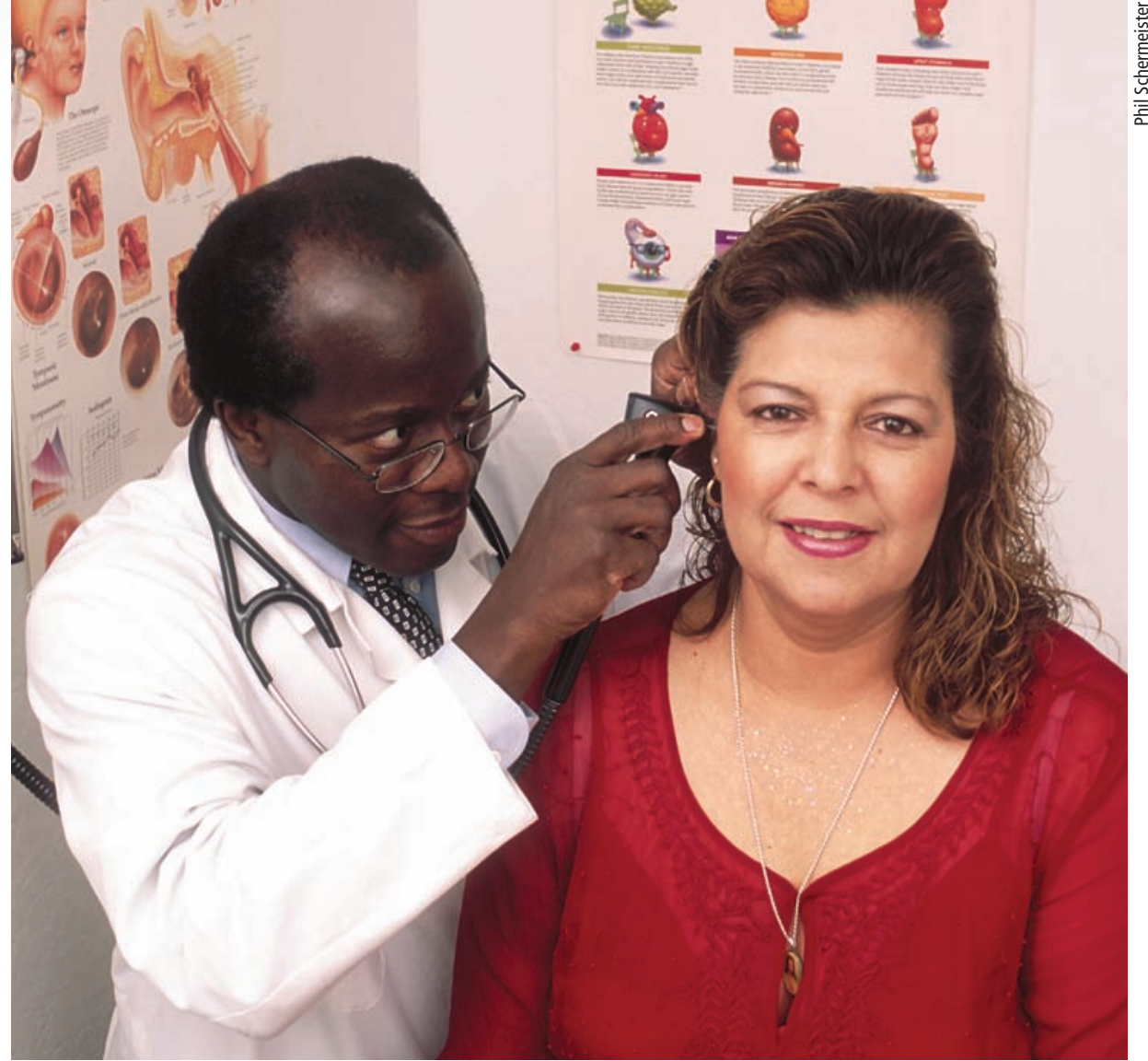

Type 2 diabetes is being diagnosed more frequently in Latinos, in whom serious complications such as amputation are more common than in non-Latino white patients.

\section{Epidemiologic trends in diabetes}

United States. The prevalence of type 2 diabetes is increasing rapidly in the United States and contibutes significantly to the rise in health care spending (Koopman et al. 2005; Thorpe 2006). Although type 2 diabetes is still more common in seniors over age 60 than in adults under age 40 , the average age at diagnosis dropped from 52 years in 1988 to 1994, to 46 years in 1999 to 2000 (Koopman et al. 2005). In fact, diabetes and other chronic health problems related to obesity are now appearing in young people at such increased frequency that today's youth may be the first generation in modern history to have a life expectancy shorter than that of their parents (Daniels 2006).

Latin America. Type 2 diabetes has also emerged as a serious health con- cern in Mexico and other parts of Latin America. Diabetes is the third major cause of mortality for the general population in Mexico and the primary cause in adults 55 years and older (Barquera et al. 2003). The dramatic rise in diabetes, hypertension and coronary heart disease in Mexico from 1980 to 1998 has paralleled an increase in obesity and may be in part related to increased intake of fat and refined carbohydrate (including soda) in that country (Rivera et al. 2002). Over the next 10 years, the number of diabetes cases in Latin America is expected to increase more than two-fold and to exceed the number of cases in the United States, Canada and Europe by 2025 (Aschner 2002). Factors driving this trend include aging of the population, urbanization, and lifestyle and dietary changes. Diagnosis often occurs late in the disease, result- 


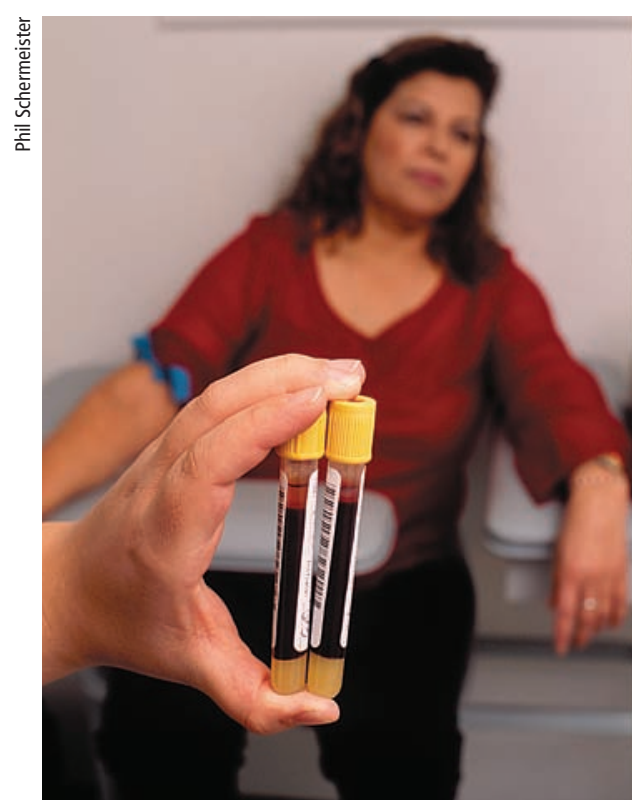

Nutrition therapy, exercise and medication can help to manage type 2 diabetes, and ongoing medical attention is critical.

ing in $10 \%$ to $40 \%$ of uncontrolled diabetes cases already having developed complications by the time of diagnosis.

Complications. U.S. adults with diabetes die from heart disease at rates that are two to four times higher than those in adults without diabetes (CDC 2007). Diabetes is the leading cause of blindness in adults 20 to 74 years old, and results in 12,000 to 24,000 new cases of blindness each year. Diabetes is also the main cause of kidney failure. In 2005, 178,689 people with end-stage renal disease due to diabetes were treated with dialysis or received a transplant. About $60 \%$ to $70 \%$ of adults with diabetes have mild to severe forms of nerve damage, including impaired sensation or pain in the hands and feet, slowed digestion of food and other nerve problems. Severe nerve damage is a major contributor to lower-extremity amputations and resulted in 71,000 amputations in 2004. Other health problems related to diabetes include periodontal disease, miscarriage, birth defects and excessively large birth weight (macrosomia) in babies born to women with diabetes.

\section{Risks in agriculture}

Relatively little research has examined diabetes and other metabolic conditions in farmworkers as either (1) predisposing factors to injury or (2) adverse outcomes from occupational exposures. Since type 2 diabetes can go undiagnosed or develop slowly over years,

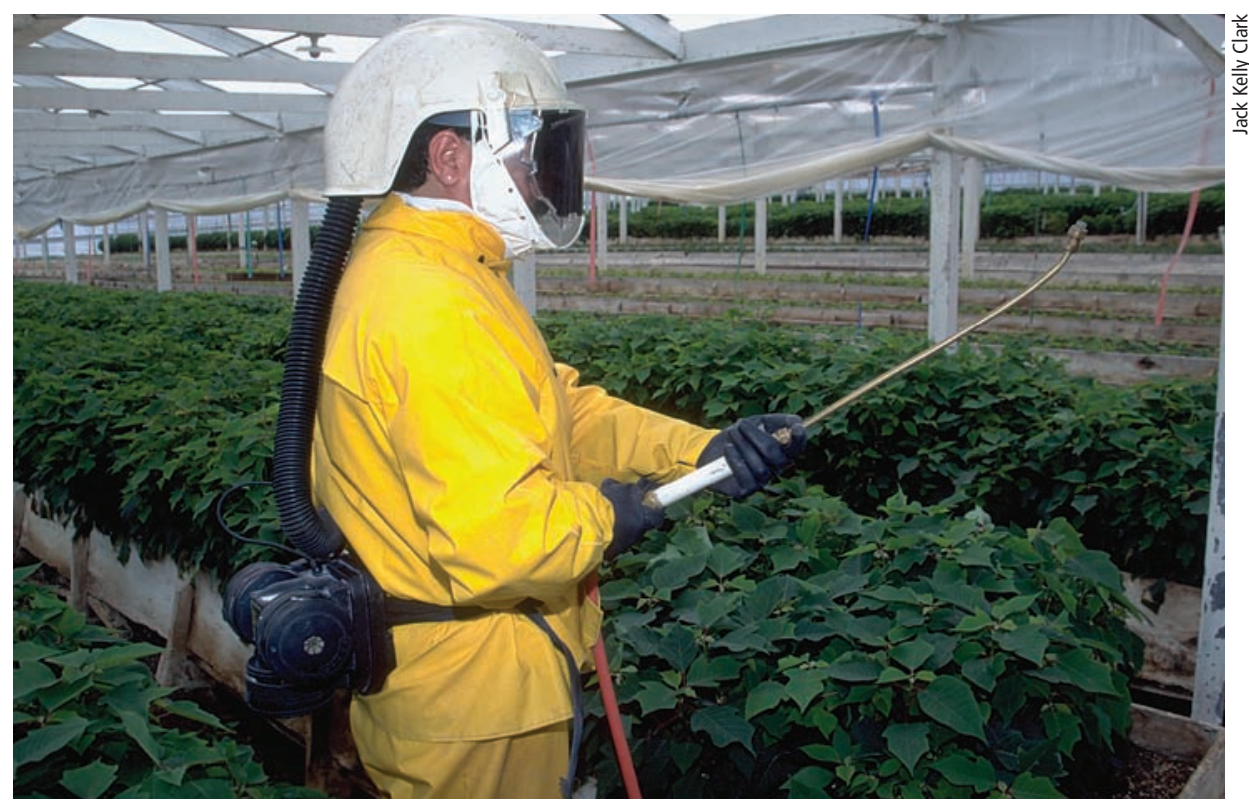

While limited research has examined occupational factors that contribute to the risk of diabetes, there is evidence of an association with environmental exposure to pesticides. Above, protective gear helps to protect a farmworker from pesticide exposure in a San Diego County nursery.

self-reported diabetes status as a variable in epidemiological studies may lead to underestimates of risk. Many people are unaware that they have diabetes. In addition to traditional, populationbased epidemiologic research, a "disease-first" approach is being taken in environmental health research (Wilson and Schwartz 2006). This paradigm emphasizes linking the understanding of molecular mechanisms of disease pathogenesis to information from traditional environmental-exposure assessments. The combination of new science tools and knowledge of early disease processes can facilitate rapid advances in knowledge of causality and individual susceptibility to environmental stressors. An example of this approach is the hypothesis that lifetime cumulative exposure to pesticides is associated with an increased risk of diabetes.

There is evidence of an association between pesticide exposure and diabetes. In a sample of 1,300 Mexican Americans who participated in the Hispanic Health and Nutrition Examination Survey, conducted from 1982 to 1984, higher levels of organochlorine compounds, which are found in pesticides, were observed in the blood of adults with self-reported diabetes compared to those without diabetes (Cox et al. 2007). However, due to the cross-sectional design of the study, it is not clear whether there is a causal relationship between pesticide exposure and diabetes, or what the nature of that relationship may be.

Metabolic conditions like diabetes that alter blood cholesterol levels may also increase the solubility of organochlorines, resulting in increased blood levels of these compounds. In a national sample of adults without diabetes, higher blood levels of organochlorine and nondioxin-like polychlorinated biphenyl compounds were associated with insulin resistance, which frequently precedes the development of type 2 diabetes (Lee et al. 2007). In the same data set, a strong dose-response relationship was observed between diabetes prevalence and the blood concentrations of six such compounds (Lee et al. 2006).

In the Agricultural Health Study, women who reported agricultural pesticide exposure (by mixing or applying pesticides to crops or repairing pesticide application equipment) were twice as likely to develop gestational diabetes (odds ratio $=2.2[95 \%$ confidence interval $=1.5-3.3]$ ) (Saldana et al. 2007). The most recent findings from this prospective study of nearly 32,000 individuals showed that lifetime cumulative exposure to seven specific chlorinated pesticides increased the likelihood of diabetes (Montgomery et al. 2008). It is recognized that the disease is multifactorial with a complex interplay between biology, the environment, lifestyles and health 


\section{Major types of diabetes}

outcomes. Overall, the results suggest that environmental exposure to pesticides may be a contributing factor for the risk of diabetes, and the hypothesis warrants further investigation.

\section{Occupational hazards}

The primary occupational hazards in agriculture include sun exposure, injuries, pesticide exposure and poor field sanitation. Exposure to extreme temperatures is challenging for individuals with diabetes. Sweat production in response to warm temperatures and exercise may be impaired in adults with diabetes (Petrofsky et al. 2005). Impaired response to temperature may partly explain why the majority of hospital admissions due to heat stroke, dehydration and heat exhaustion during heat waves occur in people with underlying metabolic conditions including diabetes, cardiovascular disease and renal problems (Semenza et al. 1999).

Agricultural workers have one of the highest rates of injury resulting in amputation (Boyle et al. 2000). The extent to which agriculture-related injuries in farmworkers are exacerbated by underlying diabetes and other metabolic diseases is not known. We do know that Latino patients with vascular disease experience higher rates of amputation than non-Latino white patients (Morrissey et al. 2007). High rates of this particular diabetes-related complication among Latinos may be due to relatively poor control of blood glucose levels and inadequate access to preventive care (Kirk et al. 2008; Oladele and Barnett 2006). Carpal tunnel syndrome occurs with increased frequency in workers with diabetes (Falkiner and Myers 2002; Werner et al. 2005). Since high levels of glucose in the blood can result in nerve damage, repetitive motions at work may exacerbate the problem.

People with type 2 diabetes need to understand that insulin may eventually be required to control blood glucose levels and that it is important not to delay insulin therapy.

\section{Prevention and management}

To prevent type 2 diabetes, the American Diabetes Association recommends lifestyle changes (ADA 2008a). Key elements include moderate weight loss, physical activity and a diet with reduced calories and total fat - especially saturated fat - and high in fiber. The extent to which these recommendations are effective in preventing diabetes in youth remains to be determined. Evidence is insufficient to recommend alcohol in moderation or foods with a low glycemic index as diabetes prevention strategies.

Management of diabetes typically involves a combination of individualized medical nutrition therapy, physical activity and medication (pills with or without insulin). Since type 2 diabetes is a progressive disease that results in the loss of pancreatic beta-cell function over time, patients need ongoing medical attention to monitor their health status and adjust medications appropriately. We have observed a cultural belief in some Mexican populations that insulin causes blindness or thins the blood. People with type 2 diabetes need to understand that insulin may eventually be required to control blood glucose levels and that it is important not to delay insulin therapy (Valitutto 2008). Knowledge about the perceptions of farmworkers regarding their risks for diabetes and how to manage the chronic disease is crucial when designing interventions (Heuer and Lausch 2006).

In 2008, the National Heart, Lung, and Blood Institute halted a large, randomized, controlled trial because very tight control of diabetes in older patients appeared to increase their risk of mortality. In that study, the intensive treatment was aimed at achieving a hemoglobin A1C (a measurement commonly used to monitor longer-term control of blood glucose in diabetes patients) value of less than $6 \%$, compared to a standard goal of $7 \%$ to $7.9 \%$. The public should not interpret this announcement to mean that the control of blood glucose in diabetes no longer matters. The American Diabetes Association's response to this news reiterated that (1) the importance of glucose control is firmly established, (2) treatment should be
Type 1 (5\% to $10 \%)$ : The body makes little or no insulin as a result of autoimmune attack on pancreatic cells. Therapy coordinates insulin injections with the individual's diet and activity patterns.

Type 2 (90\% to $95 \%$ ): Cells do not respond normally to insulin and/ or the body cannot deliver enough insulin to control blood sugar. Blood glucose control involves a healthy lifestyle and diet, and physical activity. Oral medications and/or insulin may also be prescribed.

Gestational (GDM): Onset occurs during pregnancy, and ends after delivery, but $20 \%$ to $50 \%$ of women with GDM will develop type 2 diabetes later in life. GDM is often managed with diet, but may also require insulin injections to control blood sugar.

Other: Diabetes is related to genetic abnormalities, medications or pancreatic disease.

Source: CDC 2007

\section{Current recommendations for primary prevention of diabetes in high-risk adult populations}

- Moderate weight loss (about $7 \%$ of body weight).

- Physical activity (at least 150 minutes of moderate exercise per week).

- A diet that is low in fat and calories and high in fiber (14 grams per 1,000 calories).

Source: ADA 2008a.

tailored to the individual and (3) for some older patients, intensive, tight control may not be warranted.

\section{Benefits of effective management}

Effective diabetes management decreases risk and costs. The body of evidence from randomized, controlled trials is strong that type 2 diabetes can be prevented, or at least delayed, in high-risk individuals through the adoption of a healthy lifestyle (CDC 2004). In fact, lifestyle changes can reduce the incidence of new cases by $58 \%$ and are clearly more cost-effective than providing medication to prevent diabetes in middle-aged adults (Herman et al. 2005). Compared to the standard course of treatment, intensive 


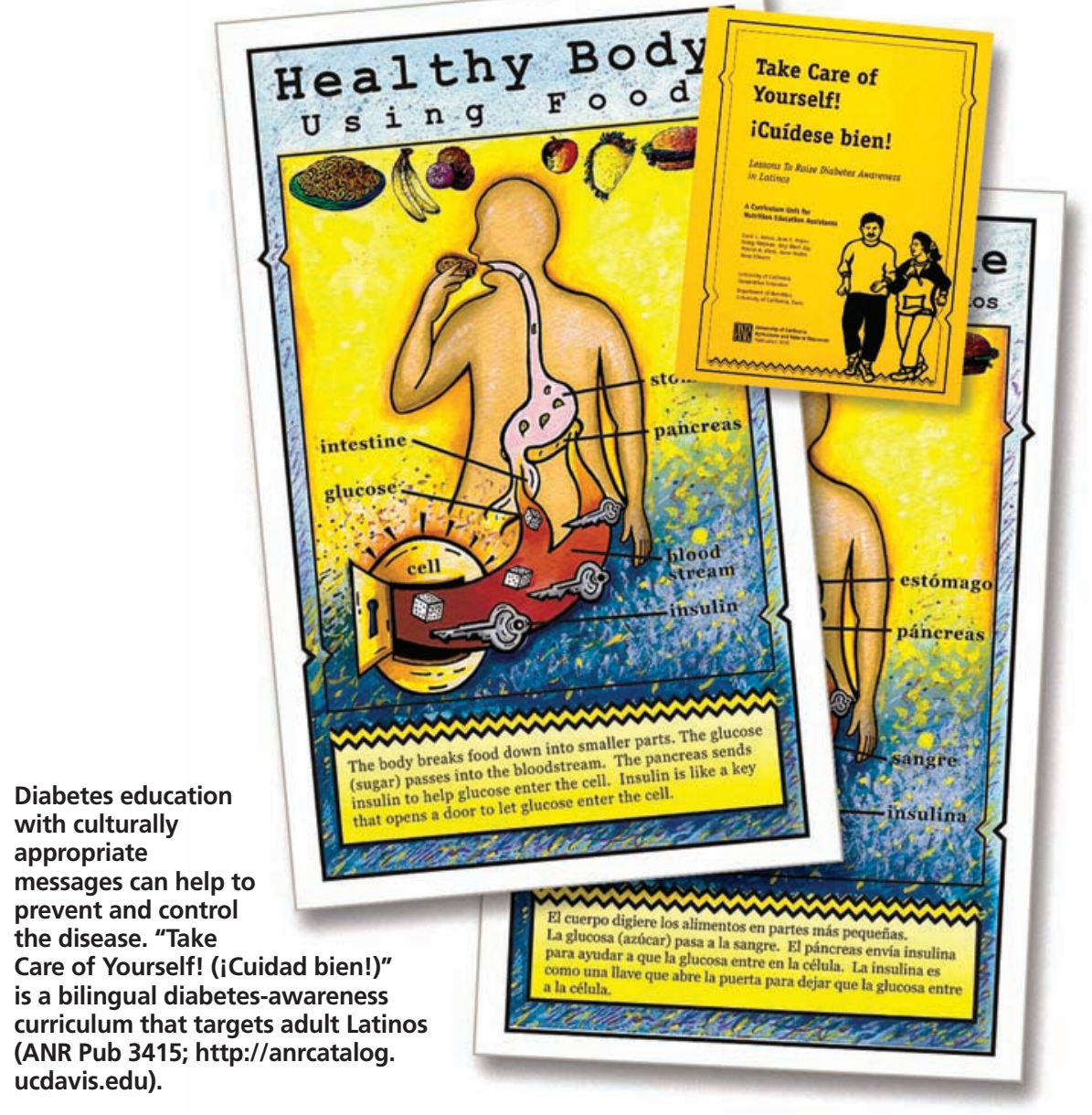

therapy for type 2 diabetes lowered the risk of cardiovascular disease and other complications (Gaede et al. 2003). To achieve those results, the intensive therapy involved individual consultations with health professionals, lifestyle changes (such as a diet low in total and saturated fat, moderate exercise and smoking cessation) and progressive changes in medication (Gaede et al. 2003). An economic analysis of 17 different diabetes interventions concluded that eye care and preconception care were clearly cost-saving, most of the other interventions were at least cost effective, and more studies are required (Klonoff and Schwartz 2000). There is an urgent need to translate the intensive diabetes therapies utilized in research studies into effective strategies for community-based health care and education.

\section{How can we make a difference?}

Farmworker access to health care is often limited, due not only to lack of insurance coverage, but also to language and cultural barriers, work schedules and lack of transportation. Lay health educators from the same communities (known in Spanish as promotoras) can help farmworkers and their families bridge the gaps in care. The role of a promotora varies from a support person or patient advocate to a teacher who can deliver basic health education in group settings or home visits. A randomized, controlled intervention among 150 Mexican-American adults with diabetes living along the U.S.-Mexico border found that promotora-taught classes were effective in improving glycemic control (hemoglobin A1C) 6 months postintervention compared to a control group that received standard clinic care only (Lujan et al. 2007). A demonstration project in a similar population reported greater improvement in glycemic control among those patients who participated more frequently in promotora-led support groups (Ingram et al. 2007).

In a report of programs funded under their Agricultural Worker Health Initiative, the California Endowment identified practices that are promising for health promotion and other key areas related to health services provided to agricultural workers (Glasnapp 2003). These practices include providing mo-
Using Hispanic radio as effective outreach to farmworkers

- There were 730 Spanishlanguage stations in 2002, up 37\% from 1998.

- Hispanic radio attracts listeners in every demographic group.

- The time spent listening is particularly on the rise in older adults (65 years and over).

- More listening is done away from home, during the morning and lunchtime hours.

- Mexican Regional, the most popular format, reaches 7.6 million listeners per week. Source: Arbitron 2007

bile clinics and child-care programs with services designed for migrant families, using the radio to reach large numbers of workers (see box above), scheduling events during the "low season" for workers and using childfocused experiences and/or popular recreational activities such as soccer to attract parents and other family members. Farmworkers and their families are excellent resources to involve in the educational process through advisory boards, outreach worker programs and promotora health programs.

UC Cooperative Extension specialists and advisors are uniquely positioned to implement many of these practices through their county connections and collaborations. Specialists and advisors have established strong networks that foster the cooperation of agricultural leaders, growers, migrant-clinic operators and community health leaders. Cooperative Extension's health promotion programs, focused on motivating participants to practice healthy eating and lifestyle behavior modifications, provide opportunities to extend the key messages so critical to diabetes prevention and awareness - eat smart, be physically active and be proactive about your health. Cooperative Extension can also play an important role in training promotoras and other extenders who work directly with farmworkers.

\section{Implications for the future}

The current trends in diabetes are projected to have staggering economic 
and social costs (Aschner 2002; Daniels 2006; Narayan et al. 2006). A conservative estimate of the direct medical and indirect expenditures attributable to diabetes was \$174 billion in 2007 (CDC 2007). That figure is projected to reach $\$ 192$ billion by 2020. The Latino population has a high prevalence of diabetes, and farmworkers often experience disparities in health care access, but there is great potential to mitigate diabetesrelated costs through culturally appropriate education aimed at primary disease prevention.

We have the capability within UC and Cooperative Extension to have a greater impact on the health and safety of the current workforce, but there are gaps to fill and collaborations that

\section{References}

[ADA] American Diabetes Association. 2008. Nutrition recommendations and interventions for diabetes: A position statement of the American Diabetes Association. Diabetes Care 31(suppl 1):S61-78.

Arbitron. 2007. Hispanic Radio Today. How America Listens to Radio http//mww arbitron.com/ downloads/hispanicradiotoday07.pdf

Aschner P. 2002. Diabetes trends in Latin America. Diabetes Metab Res Rev 18(suppl 3):S27-31.

Barquera S, Tovar-Guzman V, Campos-Nonato I 2003. Geography of diabetes mellitus mortality in Mexico: An epidemiologic transition analysis. Arch Med Res 34(5):407-14.

Boyle D, Parker D, Larson C, Pessoa-Brandao L. 2000. Nature, incidence, and cause of work-related amputations in Minnesota. Am J Ind Med 37(5):542-50.

[CDC] Centers for Disease Control and Prevention 2004. Primary prevention of type 2 diabetes mellitus by lifestyle intervention: Implications for health policy. Primary Prevention Working Group. Ann Intern Med 140:951-7.

CDC. 2007. National diabetes fact sheet: General information and national estimates on diabetes in the United States, 2007. http://www.cdc.gov/diabetes/ pubs/pdf/ndfs 2007.pdf.

Chaturvedi N. 2007. The burden of diabetes and its complications: Trends and implications for intervention. Diabetes Res Clin Pract 76(suppl 1):S3-12.

Cox S, Niskar AS, Narayan KM, Marcus M. 2007. Prevalence of self-reported diabetes and exposure to organochlorine pesticides among Mexican Americans: Hispanic Health and Nutrition Examination Survey, 1982-1984. Env Health Perspectiv 115(12):1747-52

Daniels SR. 2006. The consequences of childhood overweight and obesity. Future Child 16(1):47-67.

Falkiner S, Myers S. 2002. When exactly can carpal tunnel syndrome be considered work-related? ANZ J Surg 72(3):204-9 need strengthening. As a first step, the agenda should include interdisciplinary research to capitalize on growing collaborations between nutrition, toxicology and public-health scientists to increase understanding of the molecular mechanisms of disease pathogenesis and the associations among diet, lifestyle and environmental exposures in farmworkers and other high-risk populations. Second, more dialogue and coordination are needed between those involved in occupational health and safety programs, and health promotion and obesity/disease prevention programs. Research should examine the costs and benefits of emphasizing nutrition in general - as well as diabetes awareness and prevention — in work-

Gaede P, Vedel P, Larsen N, et al. 2003. Multifactorial intervention and cardiovascular disease in patients with type 2 diabetes. N Engl J Med 348(5):383-93.

Glasnapp JD. 2003. Identified promising practices and multicultural health models: A look at the California Endowment's Agricultural Worker Health Program. http://www.calendow.org/uploadedFiles/identified promising_practices.pdf.

Herman WH, Hoerger TJ, Brandle M, et al. 2005. The cost-effectiveness of lifestyle modification or metformin in preventing type 2 diabetes in adults with impaired glucose tolerance. Ann Intern Med 142(5):323-32.

Heuer L, Lausch C. 2006. Living with diabetes: Perceptions of Hispanic migrant farmworkers . J Comm Health Nurs 23(1):49-64.

Ingram $\mathrm{M}$, Torres $\mathrm{E}$, Redondo $\mathrm{F}$, et al. 2007. The impact of promotoras on social support and glycemic control among members of a farmworker community on the U.S.-Mexico border. Diabetes Educ 33(suppl 6):172-8S.

Kirk JK, Passmore LV, Bell RA, et al. 2008. Disparities in A1C levels between Hispanic and non-Hispanic white adults with diabetes: A meta-analysis. Diabetes Care 31(2):240-6.

Klonoff DC, Schwartz DM. 2000. An economic analysis of interventions for diabetes. Diabetes Care 23(3):390404

Koopman RJ, Mainous AG, Diaz VA, Geesey ME. 2005. Changes in age at diagnosis of type 2 diabetes mellitus in the United States, 1988 to 2000. Ann Fam Med $3(1): 60-3$.

Lee DH, Lee IK, Jin SH, et al. 2007. Association between serum concentrations of persistent organic pollutants and insulin resistance among nondiabetic adults: Results from the National Health and Nutrition Examination Survey, 1999-2002. Diabetes Care 30(3):622-8.

Lee DH, Lee IK, Song K, et al. 2006. A strong doseresponse relation between serum concentrations of persistent organic pollutants and diabetes: Results from the National Health and Examination Survey, 1999-2002. Diabetes Care 29(7):1638-44.

Lujan J, Ostwald SK, Ortiz M. 2007. Promotora diabetes intervention for Mexican Americans. Diabetes Educ 33(4):660-70. site wellness programs, with the goal of improving health outcomes. Finally, to confront the obesity and diabetes epidemics occurring in the United States and worldwide, a multidimensional approach involving both public education and environmental change is urgently needed. Such an approach will require strengthening collaboration across disciplines and programs.

\section{L.L. Kaiser is Nutrition Specialist, Department of Nutrition, UC Davis; A.C. Martin is Nutrition, Family, and Consumer Sciences Advisor, UC Co- operative Extension, San Joaquin County; and F.M. Steinberg is Chair and Associate Professor, Department of Nutrition, UC Davis.}

Montgomery MP, Kamel F, Saldana TM, et al. 2008. Incident diabetes and pesticide exposure among licensed pesticide applicators: Agricultural Health Study, 1993-2003. Am J Epidemiol 167:1235-46.

Morrissey NJ, Giacovelli J, Egorova N, et al. 2007 Disparities in the treatment and outcomes of vascular disease in Hispanic patients. J Vasc Surg 46(5):971-8.

Narayan KM, Boyle JP, Geiss LS, et al. 2006. Impact of recent increase in incidence on future diabetes burden: U.S., 2005-2050. Diabetes Care 29(9):2114-6.

Oladele CR, Barnett E. 2006. Racial/ethnic and social class differences in preventive care practices among persons with diabetes. BMC Public Health 6:259.

Petrofsky JS, Lee S, Patterson C, et al. 2005. Sweat production during global heating and during isometric exercise in people with diabetes. Med Sci Monit 11(11):CR515-21.

Rivera JA, Barquera S, Campirano F, et al. 2002. Epidemiological and nutritional transition in Mexico: Rapid increase of non-communicable chronic diseases and obesity. Public Health Nutr 5(1A):113-22

Saldana TM, Basso O, Hoppin JA, et al. 2007. Pesticide exposure and self-reported gestational diabetes mellitus in the Agricultural Health Study. Diabetes Care 30(3):529-34.

Semenza JC, McCullough JE, Flanders WD, et al 1999. Excess hospital admissions during the July 1995 heat wave in Chicago. Am J Prev Med 16(4):269-77.

Thorpe KE. 2006. Factors accounting for the rise in health-care spending in the United States: The role of rising disease prevalence and treatment intensity. Public Health 120(11):1002-7.

Valitutto M. 2008. Common crossroads in diabetes management. Osteopath Med Prim Care 2(1):4.

Werner RA, Franzblau A, Gell N, et al. 2005. Incidence of carpal tunnel syndrome among automobile assembly workers and assessment of risk factors. J Occup Environ Med 47(10):1044-50.

Wilson SH, Schwartz DA. 2006. Disease-first: A new paradigm for environmental health science research. Env Health Perspectiv 114(7):A398. 